\section{$\underset{\substack{\text { hommes } \\ \text { \& migrations }}}{ }$}

\section{Hommes \& migrations}

Revue française de référence sur les dynamiques

migratoires

$1307 \mid 2014$

L'Afrique qualifiée dans la mondialisation

\title{
Enfants des nuages, la dernière colonie,
}

Documentaire espagnol 2014 de Alvaro Longoria

\section{Anaïs Vincent}

\section{Q OpenEdition \\ 1 Journals}

\section{Édition électronique}

URL : http://journals.openedition.org/hommesmigrations/2929

DOI : 10.4000/hommesmigrations.2929

ISSN : 2262-3353

\section{Éditeur}

Musée national de l'histoire de l'immigration

\section{Édition imprimée}

Date de publication : 1 juillet 2014

Pagination : 201

ISBN : 978-2-919040-28-5

ISSN : $1142-852 X$

\section{Référence électronique}

Anaïs Vincent, «Enfants des nuages, la dernière colonie, », Hommes \& migrations [En ligne], 1307|

2014, mis en ligne le 16 janvier 2015, consulté le 22 septembre 2020. URL : http://

journals.openedition.org/hommesmigrations/2929; DOl : https://doi.org/10.4000/

hommesmigrations.2929 


\section{CINÉMA}

\section{Alvaro Longoria \\ Enfants des nuages, la dernière colonie \\ Documentaire espagnol}

Alors que le Parlement islandais vient de se proclamer en faveur de l'autodétermination du Sahara occidental, le documentaire Enfants des nuages, la dernière colonie, coproduit par Javier Bardem, revient avec un certain académisme sur l'histoire de ce conflit territorial. La mission de ce film est de réaffirmer la culture sahraouie et d'œuvrer pour la liberté des Sahraouis. Au fil des entretiens avec des témoins et acteurs de ce drame, le réalisateur Alvaro Longoria nous conduit sur les chemins sinueux de la diplomatie internationale et pénètre l'intimité de ces réfugiés parqués dans des camps.

Jusque dans les années 1970, le peuple sahraoui était nomade. "Enfants des nuages", les Sahraouis sillonnaient le désert à dos de chameau. Victoria Abril, voix off du documentaire, revient sur la genèse du conflit. Ancienne colonie espagnole, le Sahara occidental est depuis 1976 sans statut officiel selon l'Onu. Après le départ du pouvoir espagnol, il a été scindé en deux parties : $80 \%$ de son territoire sont sous la coupe marocaine, alors que les $20 \%$ restants sont administrés par les Sahraouis. Le Front Polisario, symbole de la lutte armée sahraouie, s'oppose à ces deux entités administratives. Les deux territoires sont séparés par un "mur de la honte" infranchissable entouré de mines antipersonnel, que l'équipe du film a essayé d'approcher au plus près. Soutenu par Alger, il réclame un référendum d'autodétermination.

Mais le Maroc n'est pas prêt à accepter son déroulement ni à céder ce territoire qui contribue à son essor économique. Les "provinces du Sud", comme les appellent les Marocains, recèlent de nombreux atouts. La pêche y est abondante ainsi que les productions maraîchères. Ses terres sont riches en phosphate et ses fonds sous-marins potentiellement en gaz et pétrole.

Leur exploitation imminente soulève de vives critiques du Front Polisario. La Mission pour l'organisation d'un référendum sur l'autodétermination (Minurso), déployée par l'Onu et renouvelée chaque année, a pour tâche de surveiller le cessez-le-feu mais elle n'a pas vocation à faire respecter les droits de I'homme, au grand dam d'Amnesty International et d'Human Right Watch. Les enfants et adultes réfugiés racontent avec émotion comment leur destin a été brisé. La partition de ce territoire a créé de fortes tensions. Voyant leur avenir compromis, les jeunes Sahraouis ont immigré en masse vers l'Espagne pour poursuivre leurs études. Une fois cellesci achevées, de retour dans les camps, ils sont victimes d'un fort déracinement. Javier Bardem accuse la France d'empêcher le déroulement du référendum en soutenant le Maroc. Dans ce conflit, chacun se renvoie la balle. Le Front Polisario est soupçonné de collusion avec les islamistes intégristes d'Aqmi, alors que les dérives de Rabat au Sahara occidental sont dénoncéespar les associations de défense des droits de l'homme. Anaïs Vincent 


\section{CINÉMA}

\section{Panos Koutras}

\section{Xenia}

Film grec

Panos Koutras, réalisateur du cultissime Attaque de la moussaka géante, icône du cinéma queer grec, présentait cette année à Cannes dans la catégorie "Un certain regard" son dernier long-métrage. Xenia est sorti en salle le 18juin.II sera disponible en DVD le 5 novembre prochain. Dany et Odysseas viennent de perdre leur mère, immigrée albanaise. D'Athènes, ils partent rejoindre Thessalonique pour retrouver leur père, un Grec qui les a abandonnés et dont ils se souviennent à peine. Si ce dernier reconnaît sa paternité, les deux garçons pourront obtenir la nationalité grecque. En route, ils participent à une émission télévisée populaire de découverte de jeunes talents de la chanson. Les mélodies disco de la diva italienne des années 1970, Patti Ravi, résonnent dans leur sillage. Ce road-movie acidulé témoigne avec ironie de la difficulté de s'intégrer dans une société marquée par le sceau de l'intolérance. Alors qu'ils perdent progressivement l'innocence de la jeunesse, les problèmes identitaires des enfants d'immigrés les saisissent à la gorge. Ce récit initiatique nous emmène vers la quête conjointe de leur père, de leurs origines grecques et de la célébrité. Pour fuir leurs agresseurs, ils se réfugient dans une friche, un lieu désaffecté, une sorte d'ancien hôtel : Xenia. Un titre en pied de nez à une société qui ne parvient plus à accueillir l'autre. Dans la Grèce antique, l'hospitalité est un concept majeur. Xenia est une loi respectée par les dieux grecs qui ordonnent d'honorer et d'accueillir les étrangers. Début des années 1990, la Grèce est un pôle d'immigration important après avoir été une terre de départ. Les Albanais qui fuient la pauvreté y trouvent refuge en grand nombre. Odysseas et Dany sont les enfants de ces immigrés, la deuxième génération. Ils sont nés sur le sol grec mais étrangers dans leur propre pays. En Grèce, le droit du sang prévaut sur le droit du sol. Les jeunes hommes doivent donc prouver leur origine grecque pour ne pas être expulsables à leur majorité. Le réalisateur a choisi des acteurs non professionnels, Kostas Nikouli et Nikos Gelia, eux-mêmes d'origine albanaise, pour interpréter ses deux héros. Pour lui, il est important d'avoir expérimenté une situation pour la traduire à l'écran. Sujet à la discrimination de la part des deux communautés, Dany assiste à Athènes au lynchage d'Albanais par des extrémistes grecs. Le parti néonazi Aube dorée s'enracine dans le paysage politique. Depuis les dernières élections, deux députés siègent au Parlement européen. Suite à l'assassinat du rappeur anti-fasciste Pavlos Fyssas, les membres de ce parti sont tous à présent sous contrôle judiciaire ou en détention provisoire pour appartenance à une organisation criminelle. Dany est la victime de ces milices fascistes, mais il est également rejeté par une partie de la communauté albanaise homophobe.

Entrecriseéconomiqueettensionsintercommunautaires, Panos Koutras dresse un portrait sombre de son pays, théâtre de violences. Dans un clin d'œil autobiographique, il réaliseavechumourunpamphlet corrosif contre une société sclérosée par l'intolérance. A. V. 